\title{
Delimiting species: a Renaissance issue in systematic biology
}

\author{
Jack W. Sites Jr and Jonathon C. Marshall \\ Department of Integrative Biology and M.L. Bean Life Science Museum, Brigham Young University, Provo, UT 84602-5181, USA
}

\begin{abstract}
The literature about species concepts might be larger than that about any other subject in evolutionary biology, but the issue of empirically testing species boundaries has been given little attention relative to seemingly endless debates over what species are. The practical issue of delimiting species boundaries is nevertheless of central importance to many areas of evolutionary biology. The number of recently described methods for delimiting species suggests renewed interest in the topic, and some methods are explicitly quantitative. Here, we review nine of these methods by summarizing the relevant biological properties of species amenable to empirical evaluation, the classes of data required and some of the strengths and limitations of each.
\end{abstract}

Systematic biology rests on an extensive literature about the theory and methodology of phylogenetic inference and the theory of species concepts [1-3], but on a relatively small literature about the methods of delimiting species [4]. This state of affairs is rather odd given that two frequently stated empirical goals of systematic biology are to: (1) discover MONOPHYLETIC (see Glossary) groups at higher levels; and (2) discover lineages (i.e. species [5]) at lower levels [6]. Interest in delimiting species and inferring speciation patterns and mechanisms was high during the mid-20th century era of the 'New Systematics' [7], after which activity declined [4], but there are now signs of a Renaissance, and some novel methods have recently been proposed for testing species boundaries in a statistically rigorous framework [8-11]. From the broader perspective of evolutionary theory, delimiting species is important in the context of understanding many evolutionary mechanisms and processes. Demographic structure within a species is frequently extensive [12], and this intraspecific structure will probably influence the rates at which novel adaptations originate and spread among demes $[13,14]$, whereas the species boundary will define the limits within or across which evolutionary processes operate [15]. Over- or under-resolving species boundaries will obviously confound studies aimed at understanding these population-level processes. Species are also routinely used as fundamental units of analysis in biogeography, ecology, macroevolution and conservation biology [16-20], and a better understanding of these larger scale processes requires that systematists employ methods to delimit objectively and rigorously what species are in nature.

Here, we review nine methods of delimiting species chosen to show a range of differences with respect to the biological properties of species that can be empirically tested, the types of data needed (DNA, morphology, etc.), the density of population sampling required, and the generality of implementation (bisexual taxa only versus bisexuals and asexuals). Our review is incomplete, as other methods [9,21-24] could not be included owing to space limitations. To place operational methods into context, we briefly make a distinction between the issue of defining what species are versus the issue of how these entities can be delimited [1]. Mayden [2] recognized the lineage-based evolutionary species concept as a general theoretical definition of species, and considered all other definitions as 'secondary' operational tools for species recognition. De Queiroz [3] made parallel arguments for a 'general lineage concept', and considered all variants of that concept to treat different properties of diverging lineages as properties of species. He proposed that a unified species concept could be achieved by rejecting the interpretation of any of the properties in question (i.e. reproductive isolation, ecological distinctiveness, diagnosability, monophyly, etc.) as necessary properties and instead treating them as lines of evidence relevant to inferring species limits. The subject matter of our review deals with methods relating to the detection of different properties of lineages, which, for convenience, we partition into non-tree based and tree-based approaches; we

\footnotetext{
Glossary

Allozyme: an allele of an enzyme, as identified by electrophoresis. Exclusivity: property of a group in which all members of the group share a more recent common ancestor with every other member of the group than any of them does with any non-member.

Gene conversion: nonreciprocal recombination processes resulting in a sequence becoming identical with another.

Lineage sorting: stochastic fixation or extinction of alternate alleles at a locus in descendant lineages of a polymorphic ancestral population.

Monophyly: the property of a taxon being composed of an ancestor and all of its descendants.

Nei distance/identity: transformation of allelic or genotypic frequency data into a single pairwise metric of similarity/difference.

Nested clade distance: measures the geographical spread of a clade and how a clade is geographically distributed relative to other clades in the same or higher-level (more inclusive) nesting category.

Synapomorphies: shared derived characters.

Tokogeny: the descent of organisms (as opposed to species).
} 
deliberately avoid the confusing terminology associated with many secondary concepts $[2,23]$.

\section{Non-tree based methods}

These methods focus on delimiting species based on indirect inferences of the presence or absence of gene flow.

\section{Hybrid zone barrier ( $H Z B)$}

Porter [25] used gene flow statistics (with ALLOZYMES) to test species boundaries in two hybridizing North American butterfly species (genus Limenitis); his method derives from Wright's [26] equilibrium relationship between gene flow and genetic differentiation, and requires an estimate of gene flow (measured as the number of migrants $\mathrm{Nm}$ ) between sympatric sibling species to assess the strength of biases in the estimator, $N \mathrm{~m}$, before applying it to hybridizing populations. Because presumably no gene flow currently occurs between sympatric species, a result showing $N \mathrm{~m}>0$ is attributed to other factors causing genetic similarity between populations. $N \mathrm{~m}$ is also estimated among subpopulations within a species, and is used to determine values expected for conspecifics; here, $N \mathrm{~m}$ estimates provide an approximate upper bound at panmixia or random mating $(\mathrm{Nm}>1.0)$. One then estimates $\mathrm{Nm}$ across a hybrid zone between candidate species, under the null hypothesis that the hybridizing populations are genetically isolated. Porter determined by empirical comparisons the expected upper and lower bounds of $\mathrm{Nm}$ under this sampling design, and showed that estimates of gene flow not significantly greater than those typical of sympatric sibling species would support an hypothesis that the hybridizing populations were two species. In his examples of empirically determined limits, a $N \mathrm{~m}>\sim 1.0$ between hybridizing populations suggests that gene flow is the predominant cause of genetic similarity between the groups, whereas a $N \mathrm{~m}$ between 0.5 and 1 suggests that gene flow is weak but probably sufficient to enable the rapid exchange of selectively favoured alleles (i.e. the hybridizing populations were not genetically isolated).

\section{Genetic distance: Good and Wake $\left(G e n D_{G W}\right)$}

This method, described by Good and Wake [27], analyzes genetic differentiation as a function of spatial separation, based on a plot of pairwise (allozyme) genetic distances versus geographical distances. A regression line is fitted to a set of points representing pairs of populations from a priori defined subsets of samples (e.g. all from a single river basin, etc.), and if the regression line passes through the origin, the samples are interpreted as being conspecific, because this pattern is most readily explained by gene flow with isolation-by-distance. Conversely, the regression for samples that include genetically isolated groups will deviate significantly from a 0 origin, because genetic divergence among samples is expected to be independent of their degree of geographical separation (Fig. 1).

\section{Genetic distance: Highton $\left(G e n D_{H}\right)$}

Following a different line of reasoning, Highton [28,29] suggested that, for some groups characterized by

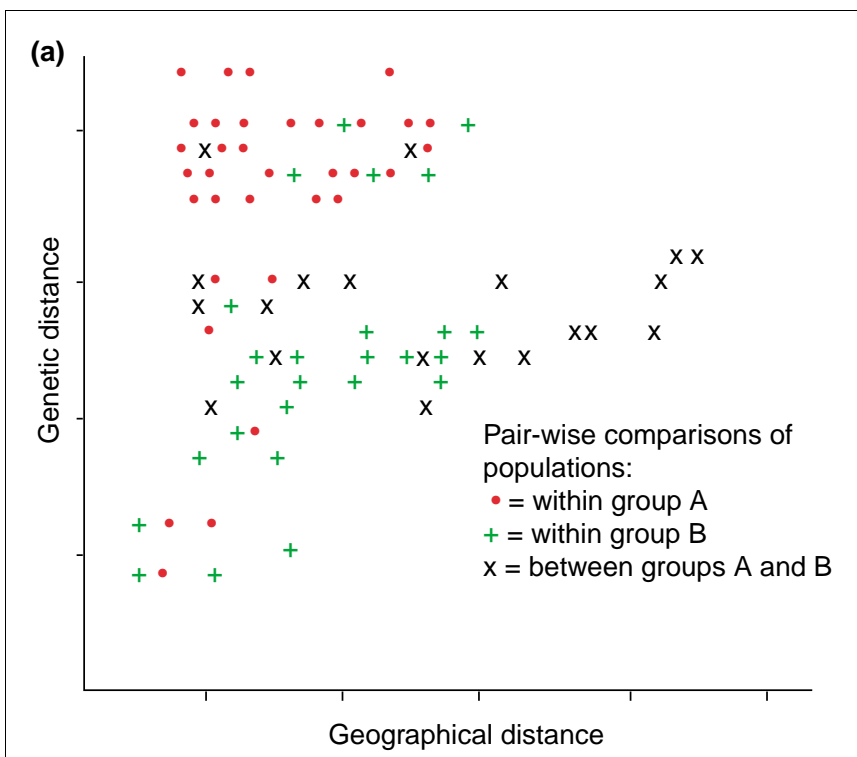

Regression comparisons to be made:

(b) Within groups $\mathrm{A}(\cdot)$ and $B(+)$

(c) Between groups $\mathrm{A}$ and $\mathrm{B}(\mathrm{x})$
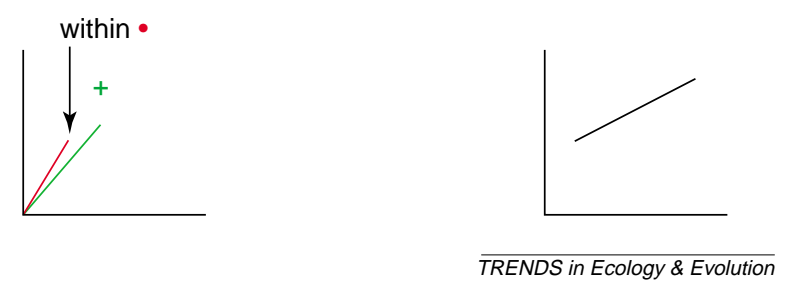

Fig. 1. Genetic distance - Good and Wake $\left(G_{e n D_{G W}}\right)$ method. (a) Bivariate plot method of Good and Wake [27] showing the relationship between genetic distance and geographical distance for pairwise comparisons of two populations of interest (identified as groups $A$ and $B$ ). This test requires a regression analysis for comparisons within proposed species groups (A and $B$ ), and a second iteration of regressions between all paired combinations of proposed groups (A versus $B$ ). Evidence for genetic cohesion is provided when a regression line passes through the origin, and the steepness of its slope reflects the geographical scale over which gene flow presumably occurs [steeper slopes reflect relatively greater differentiation (for the same geographical distances) or relatively smaller geographical distances (for the same amount of differentiation)]. (b) Within-group regressions for hypothetical groups shown in (a); all lines pass through the origin, but slope differences reflect variable geographical scales (horizontal axis) over which samples are distributed. (c) The hypothetical between group regression which deviates from the origin; this is the expected pattern when two groups being compared do not form a single genetically cohesive group.

extremely slow rates of morphological evolution (e.g. salamanders of the family Plethodontidae), species boundaries are most easily identified by multilocus allozyme data from which genetic distances are calculated and used to infer the distance that correlates with intrinsic reproductive isolation. Specifically, he argued that groups of samples differing by a NEI Genetic Distance (Nei D) [30] of 0.15 or higher should be considered distinct species. Highton recognized that this value was arbitrary, but cited an earlier study [31] suggesting that allopatric populations differing by fixed alternative alleles at $15 \%$ of their loci were probably different 'biological species'. Highton also noted that most (97\%) pairwise Nei identity (Nei I) between well defined species of vertebrates are $<0.85$, whereas most $(98 \%)$ values within species are $>0.85$ [a Nei I of 0.85 is $\approx$ a genetic distance (D) of 0.16 ] [32]. These 
patterns are general enough across non-avian vertebrates to suggest that, as a rule of thumb, the divergence needed to complete speciation is correlated with a $\mathrm{D} \approx 0.15-0.16$. Operationally, the method is implemented by plotting a histogram of $\mathrm{D}$ value frequencies for pairwise comparisons between populations [33]; the distribution should be approximately unimodal with values clumping below $\mathrm{D} \approx 0.15$ under a hypothesis of conspecificity [34]. If the samples comprise different species, then the distribution of $D$ values is expected to be bimodal, with a second peak well above $\mathrm{D}=0.15$. This method assumes that reproductive isolation is based on divergence across many loci scattered throughout the genome [35], and that allozyme loci diverge in an approximately clock-like manner, so as to correlate with, and serve as a signature for, the emergence of reproductive isolation (see also $[33,34]$ ).

\section{Testing a 'field for recombination'}

A method described by Doyle [36] tests species limits by using nuclear loci (under mendelian transmission) to identify a field for recombination (FFR) [37] which should be coincident with the boundaries of species in which constituent populations are interconnected by gene flow. The basic premise is that mutually exclusive clades of alleles are not always indicative of bisexual species boundaries, given the heterogeneous genealogies of multiple loci [38,39]. The persistence of mutations that appear as SYNAPOMORPHIES on a gene tree will reflect both processes operating at the sequence level (mutation, recombination, and GENE CONVERSION) and demographic processes (gene flow, genetic drift, and natural selection) operating at the level of the whole organism [40]. The main premise of the FFR method is that allele fixation/absence are the ends of a frequency continuum produced by processes that involve whole organisms, and Doyle [36] argues that the distribution of alleles will track organismal histories more faithfully than will topologies of the same alleles. The method is explicitly non-topological and seeks to identify discontinuities between FFRs on the basis of non-overlapping sets of heterozygous individuals (heterozygotes provide evidence for recombination within a single gene pool), and the best resolution of gene pool boundaries will be resolved via use of multiple unlinked loci to define the FFRs (Fig. 2).

\section{Population aggregation analysis}

Davis and Nixon [41] described population aggregation analysis (PAA) on the basis of two principles: (1) all individuals of a local population are regarded as belonging to the same species; and (2) individuals sharing identical character attributes drawn from two different populations provide evidence for conspecificity. This method is a formal coding of the traditional, standard methodology for delimiting species based on one or more diagnostic morphological character differences. The PAA requires that character states be summarized for all individuals in a sample to estimate a population 'profile' for those states, and samples with identical population profiles are then combined. This process is continued iteratively until the only remaining sample aggregates are those separated from each other by fixed character state differences, and



Fig. 2. Field for recombination (FFR) method. Hypothetical example of inferring a FFR in a bisexual species, as described by Doyle [36]. (a) Single-locus FFR; in this case a sample of eight individuals is scored at a single Mendelian locus, and shown to segregate for seven alleles. The vertical dotted line marks the discontinuity between two allele pools identified by nonoverlapping heterozygous genotypes; this is the inferred boundary between two FFRs. (b) A contrived phylogeny of these same seven alleles from (a); neither FFR is monophyletic for the alleles defining it. (c) Multilocus FFR; seven individuals are scored at two unlinked mendelian loci, and the FFR defined as above for each locus. This step is followed by combining the two FFRs into one, and using the overlap of composite FFR scores to define the multilocus FFRs; the two groups so defined are taken to be the species.

these are taken to be species. Box 1 summarizes implementation of the PAA.

\section{Tree-based methods}

These methods differ from those above in that all delimit species on the basis of properties related to phylogenetic tree topologies (monophyly, concordance with geography, etc.)

\section{Cladistic haplotype aggregation (CHA)}

Brower [42] implemented this method by collecting DNA sequences (haplotypes) of individuals as representatives of local populations, and then, as with the PAA, tabulating sample haplotypes to determine the population profiles, and aggregating samples sharing identical profiles. This method then estimates the phylogeny of the unaggregated groups of haplotypes, and divides sets of topologically contiguous populations into separate species. All members of a species form a contiguous section of an unrooted tree and are separated from all other populations by a branch along which character state change leading to a fixed character difference is inferred; these groups will '....corroborate or reject specific a priori hypotheses of species boundaries' [42]. 


\section{Box 1. Delimiting species by population aggregation analysis}

Here, we present a contrived example (Table I) illustrating the population aggregation analysis (PAA) described by Davis and Nixon [41]. In this example, lower case letters designate individuals sampled from the same locality (1, 2 and 3$)$, and these individuals are taken to be members of the same interbreeding group. The characters (capital letters and numbers in the body of the table) scored for each individual are the biological attributes listed across the top of the Table (1-8). To implement the PAA, attribute profiles are scored for all individuals $(a, b, c$, etc.) by locality, and a population profile is then developed for each attribute according to whether that attribute is identical in state in all individuals in the sample. If so, then the population profile is scored as 'fixed' for that attribute, and it is recognized as a 'character' (invariant in the sample). The same procedure is then followed for other samples; population profiles are inferred for all attributes, and these samples then sequentially compared to the first, and either grouped with it (if no fixed character state exists between populations), or maintained separately. Attributes that are polymorphic (for at least one shared character state) within a sample are defined as 'traits' (scored as ' \pm ') and deemed to be unimportant in defining species boundaries unless polymorphisms do not overlap. The method proceeds by iterative aggregations of populations until the process terminates with the recognition of the smallest groups of populations diagnosed by fixed character combinations.

In this example, we have arbitrarily defined attributes $1-4$ as those that can be coded as discrete alternative states $(0,1$, etc.; attributes 1-3 are binary, whereas 4 is multistate), and others might represent mendelian markers, such as chromosomes or allozyme loci, and thus are scored as diploid genotypes (attributes $5-8$ ). In sample 1 , attributes 1,2,5 and 7 are scored as characters inferred to be fixed for states 1, 0, AA and BB, whereas attributes $3,4,6$ and 8 have polymorphic $( \pm)$ states. The aggregate population profiles inferred for these three samples support recognition of two distinct species; localities 2 and 3 are combined because no attributes are fixed for alternative states between them, but locality 1 can be diagnosed relative to the others by attributes 1 and 7 (fixed for alternative states) and 4 and 8 (fixed for alternative polymorphisms).

Table I. Hypothetical example of the implementation of population aggregation analysis

\begin{tabular}{|c|c|c|c|c|c|c|c|c|}
\hline \multirow[t]{2}{*}{ Sample individual } & \multicolumn{8}{|c|}{ Biological attributes } \\
\hline & 1 & 2 & 3 & 4 & 5 & 6 & 7 & 8 \\
\hline \multicolumn{9}{|l|}{ Locality 1} \\
\hline a & 1 & 0 & 1 & 1 & AA & $A B$ & BB & $A B$ \\
\hline$b$ & 1 & 0 & 1 & 2 & $\mathrm{AA}$ & $A C$ & BB & $A B$ \\
\hline c & 1 & 0 & 0 & 1 & AA & BB & BB & AA \\
\hline d & 1 & 0 & 1 & 2 & AA & $A B$ & BB & BB \\
\hline e & 1 & 0 & 1 & 1 & AA & AA & $\mathrm{BB}$ & $A B$ \\
\hline$f$ & 1 & 0 & 1 & 2 & $\mathrm{AA}$ & $A B$ & BB & $A B$ \\
\hline $\begin{array}{l}\text { Popul. profile } \\
\text { Locality } 2\end{array}$ & 1 & 0 & \pm & \pm & AA & \pm & BB & \pm \\
\hline a & 0 & 0 & 1 & 3 & AA & $A B$ & $\mathrm{CC}$ & $C D$ \\
\hline b & 0 & 0 & 1 & 4 & AA & $A B$ & $\mathrm{CC}$ & DD \\
\hline c & 0 & 0 & 0 & 3 & $\mathrm{AA}$ & $\mathrm{AA}$ & $\mathrm{CC}$ & $C D$ \\
\hline d & 0 & 0 & 1 & 4 & $\mathrm{AA}$ & $A B$ & $\mathrm{CC}$ & $C D$ \\
\hline $\begin{array}{l}\text { Popul. profile } \\
\text { Locality } 3\end{array}$ & 0 & 0 & \pm & \pm & AA & \pm & $\mathrm{CC}$ & \pm \\
\hline a & 0 & 1 & 1 & 3 & AA & $A B$ & DD & EE \\
\hline$b$ & 0 & 1 & 0 & 4 & AA & $A B$ & DD & EE \\
\hline c & 0 & 1 & 1 & 3 & AA & $\mathrm{AA}$ & $C D$ & EE \\
\hline d & 0 & 0 & 0 & 3 & $\mathrm{AA}$ & $A B$ & DD & EE \\
\hline e & 0 & 1 & 1 & 3 & AA & BB & DD & DE \\
\hline$f$ & 0 & 1 & 0 & 4 & AA & $A B$ & DD & EE \\
\hline g & 0 & 1 & 1 & 3 & AA & $A B$ & DD & $\mathrm{EE}$ \\
\hline $\mathrm{h}$ & 0 & 1 & 0 & 4 & AA & $\mathrm{AB}$ & DD & $\mathrm{EE}$ \\
\hline I & 0 & 1 & 1 & 3 & AA & $A B$ & DD & $\mathrm{EE}$ \\
\hline Popul. profile & 0 & \pm & \pm & \pm & AA & \pm & \pm & \pm \\
\hline
\end{tabular}

The exclusivity criterion (EXCL)

Baum and Shaw [43] described a method to delimit 'genealogical species' based on two requirements: (1) species are basal taxa - they must not themselves contain taxa; and (2) species reside at the boundary between reticulate and divergent genealogy, where unlinked genes should have concordant genealogical histories. Species are therefore defined as exclusive groups; those in which all members are more closely related to each other than to any organism outside of the group, and these can only be delimited when relationships are hierarchical [43]. The method requires the reconstruction of genealogies for unlinked loci collected from the same individuals, then a strict consensus of the trees is taken to define points of concordance (resolved nodes), and species are delimited by exclusive nodes.

\section{DNA/morphological genealogy}

Wiens and Penkrot [11] described protocols (the WP methods) for DNA and morphological tree-based methods for delimiting species. The DNA method is intended to be used in combination with a nested clade analysis (NCA; [44]), and is based on a sampling design that ideally should include: (1) as many closely related reference species to increase the strength of the EXCLUSIVITY test for the focal species; and (2) sampling of at least two individuals from as many localities as possible to increase the strength of the between-population gene flow inferences. The DNA method assumes a phylogeny of nonrecombining haplotypes of known locality and taxonomic designation, and that failure of haplotypes from a given locality to cluster together is potential evidence for gene flow with other populations. The tree-based morphological method is based on population (rather than individual) sampling, to avoid biased treatment of polymorphisms shared between populations as homoplasies rather than synapomorphies, and considers sets of populations that are strongly supported, exclusive and concordant with geography as species. The focal species can also be a single, nonexclusive species if the basal clades of populations are weakly supported, discordant with geography and appear on adjacent branches of the phylogeny (such that the focal species is paraphyletic). Both DNA and morphological tree-based methods can be implemented using simplified flow charts that lead to several other alternatives (Box 2 summarizes an example).

\section{Templeton's tests of cohesion (TTC)}

Extensions of Templeton's views about genotypic and phenotypic cohesion include tests of species boundaries $[10,45]$ that acknowledge the influence of both historical and ongoing demographic processes on population genetic structure. The approach uses both properties to delimit species in a manner that can be statistically tested through a set of nested null hypotheses that evaluate the correlation of genotypes and/or phenotypes with geographical location (the NCA [44]). The protocol tests two hypotheses: $\left(\mathrm{H}_{1}\right)$ organisms sampled are derived from a single evolutionary lineage; and $\left(\mathrm{H}_{2}\right)$ populations of lineages identified by rejection of $\mathrm{H}_{1}$ are 'genetically exchangeable' (e.g. sexually reproducing species are 


\section{Box 2. Testing species boundaries in the lizard genus Sceloporus}

Wiens and Penkrot [11] described explicit tree-based methods for species delimitation using morphological and DNA data, and compared both to a character-based approach (with morphology) to infer species boundaries in lizards of the polymorphic Sceloporus jarroviicomplex. Morphological and molecular (mtDNA) data sets included samples collected at the type localities for seven recognized subspecies of $S$. jarrovii, and eight other species of the $S$. torquatus group as nonfocal species. In all analyses, the shortest trees were recovered using options in PAUP [69], with support assessed by nonparametric bootstrapping. Figure I (redrawn, with permission, from [11]) illustrates the methods, species $A$ and $B$ are the focal and nonfocal species, respectively, and the numbers encircled in coloured lines represent different localities for each species (1-4)

(a)
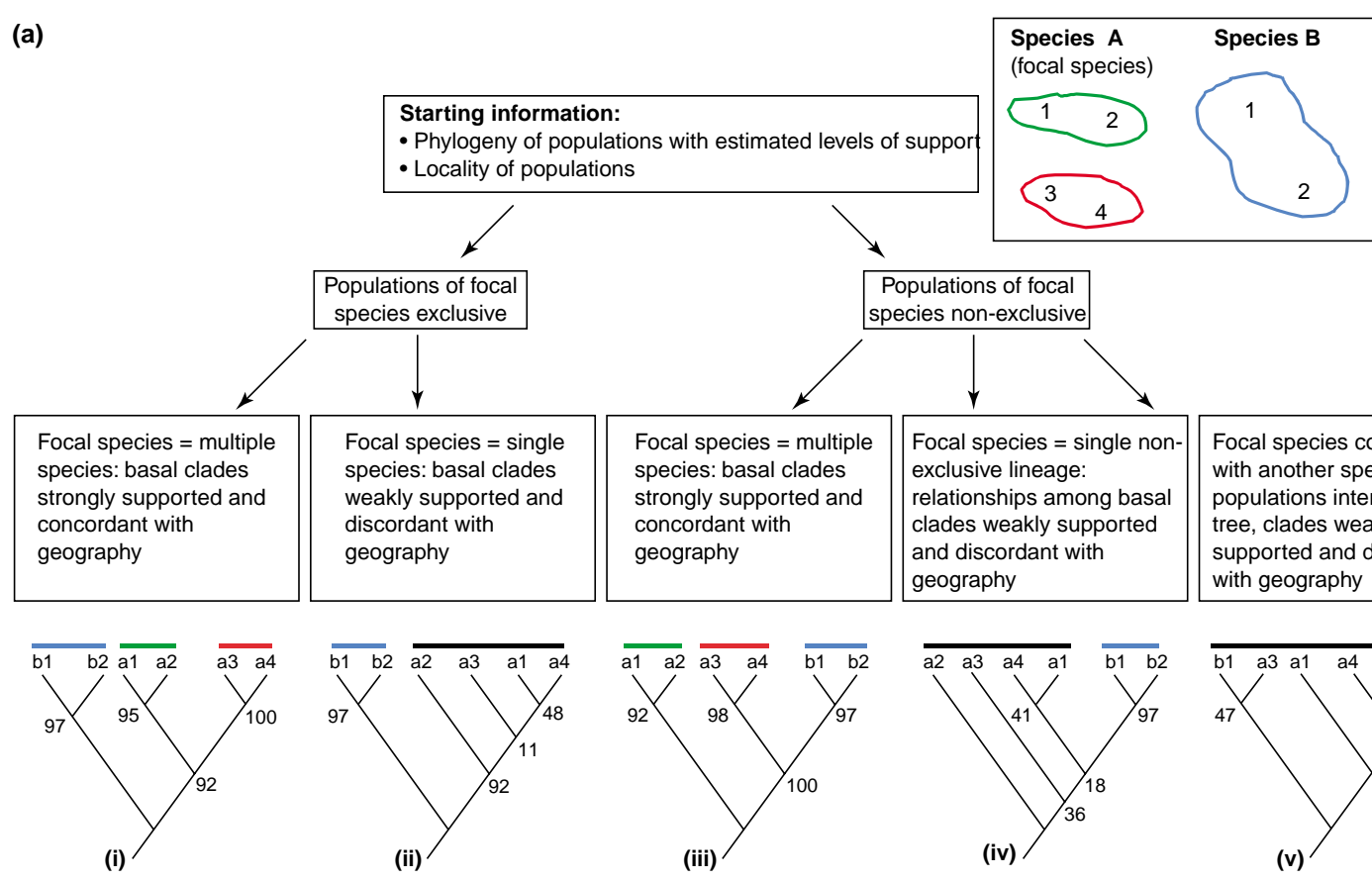

(b)



Starting information:

- DNA haplotype phylogeny

Locality of haplotypes

Species assignment of localites

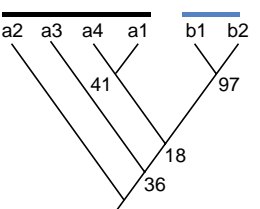

(iv)



with geography



(ii)

\begin{tabular}{|l|l|l|l|}
\hline $\begin{array}{l}\text { Focal species is non-inclusive } \\
\text { with respect to one or more } \\
\text { distinct, exclusive species }\end{array}$ & $\begin{array}{l}\text { Haplotypes of focal species } \\
\text { interdigitate with those of a } \\
\text { non-exclusive species }\end{array}$ \\
\hline $\begin{array}{ll}\text { species }= \\
\text { Focal species }= \\
\text { single non- } \\
\text { exclusive lineage: } \\
\text { gene flow between } \\
\text { basal lineages } \\
\text { of focal species }\end{array}$ & $\begin{array}{l}\text { Multiple species: } \\
\text { no gene flow } \\
\text { between basal } \\
\text { lineages of each } \\
\text { species }\end{array}$ & $\begin{array}{l}\text { Focal species } \\
\text { conspecific } \\
\text { with another } \\
\text { species: gene } \\
\text { flow between } \\
\text { species }\end{array}$ \\
\hline
\end{tabular}

\begin{tabular}{l|l}
$\begin{array}{l}\text { lineages of } \\
\text { focal species }\end{array}$ & $\begin{array}{l}\text { basal lineages } \\
\text { of focal species }\end{array}$ \\
\hline
\end{tabular}


(iii)


(iv)

(v)

$\overline{T R E N D S}$ in Ecology \& Evolution

Fig. I. 


\section{Box 2. continued}

Both tree-based tests require genealogies for samples comprising the focal species (Species A in Fig. I), along with one or more closely related non focal species (Species B), and then follow a dichotomous inference key to draw conclusions about species boundaries (compare trees (a) i -v and (b) i - vi in Fig. I; coloured lines denote clades concordant with geography, whilst black lines connect terminals reflecting geographic discordance). However, these differ in two important respects: (1) population samples are terminals for morphology (Fig. la), whereas individuals or haplotypes are terminal units for DNA (Fig. Ib); and (2) failure of individuals from the same locality to cluster together is potential evidence for gene flow between localities for DNA, whereas weak support and discordance of population-level clades with geographic proximity of localities is evidence for gene flow for morphology.
All approaches resolved five species, but only two species were fully congruent among all methods (Table I). The mtDNA analysis showed that the $S$. jarrovii haplotypes did not form an exclusive group, but were recovered as five clades, none of which were sister taxa. These clades were allopatric with respect to each other and concordant with geography, and were recognized as species, in spite of some discordance with morphological data. Most of the discord was attributed to patterns of morphological variation characterized by low between-species relative to high within-species variation, a worst-case scenario for species delimitation [11]. The surprising discordance between the character-based and tree-based morphological methods was probably due to this same pattern; this was the first study in which clearly articulated alternative methods of delimiting species were rigorously assessed for concordance.

Table I. Comparison of results for the tree-based and the character-based methods for delimiting species in lizards of the Sceloporus jarrovii complex ${ }^{\mathrm{a}, \mathrm{b}}$

\begin{tabular}{|lll|}
\hline mtDNA-tree & Morphology tree & Morphology character \\
\hline S.j. cyanostictus & S.j. cyanostictus & S.j. cyanostictus \\
S.j. sugillatus & S.j. sugillatus & S.j. sugillatus \\
S.j. jarrovii $(+$ S. lineolateralis) & S.j. jarrovii & S.j.jarrovii + S.j.minor + S.j. oberon \\
S.j.oberon + northern S.j.minor & S.j. oberon & One population of S.j.minor \\
S.j. erythrocyaneus + southern & S.j. erythrocyaneus + S.j. immucronatus & S.j. erythrocyaneus + S.j. immucronatus + \\
S.j. minor + S.j. immucronatus & & all S.j. minor \\
\hline
\end{tabular}

\section{${ }^{\mathrm{a}}$ From [11].}

${ }^{\mathrm{b}}$ Note the different results obtained from the different morphological approaches. interconnected by gene flow) and/or 'ecologically interchangeable' (e.g. sexually reproducing species that might have allopatric populations, or asexually reproducing species, share among conspecifics the same adaptations and environmental tolerances). Species are recognized only after rejection of both hypotheses at the same levels of divergence.

Specifically, one tests $\mathrm{H}_{1}$ by constructing haplotype networks, calculating NESTED CLADE DISTANCE measures from the networks, and testing for statistically significant associations of nested clades with geographic locations [46]. If significant associations are found at one or more clade levels, one then follows an inference key [45] to discriminate among different biological processes that might cause the significant association. One such explanation that might be inferred is historical fragmentation at some clade level, and this is the only inference that provides evidence for the possible existence of separate evolutionary lineages, and requires the rejection of $\mathrm{H}_{1}$.

After rejecting $\mathrm{H}_{1}$ under an inference of historical fragmentation, there is now the possibility that the two or more lineages inferred to be in the sample constitute different cohesion species. The next step is then to test $\mathrm{H}_{2}$, that the lineages defined by the fragmentation event(s) are genetically exchangeable and/or ecologically interchangeable [10]. $\mathrm{H}_{2}$ can be evaluated by once again performing NCA to test for a statistical concordance of candidate traits for genetic exchangeability (e.g. those associated with prevention or promotion of gene flow, including premating isolating/fertilization mechanisms, mate-recognition systems, etc.) with the evolutionary lineages defined in the rejection of $\mathrm{H}_{1}$. Similarly, the same can be done for candidate traits for ecological interchangeability (life-history traits, habitat requirements or preferences, physiological tolerances/ adaptations; [45,47-49]). $\mathrm{H}_{2}$ is rejected by a significant association of either set of candidate traits and the previously identified evolutionary lineages, and the lineages are inferred to be distinct cohesion species if $\mathrm{H}_{2}$ is rejected at the same clade level at which $\mathrm{H}_{1}$ was rejected with the inference of historical fragmentation.

\section{Prospects}

Table 1 summarizes the methods relative to biological properties and criteria, the kinds of data suitable, and some assumptions and limitations of each. Five methods refer explicitly or implicitly to gene flow and apply only to bisexual species, whereas others (PAA, CHA, EXCL and WP), in part, emphasize the TOKOGENY-phylogeny interface (i.e. gene flow inference is part of the method), but could be used to detect asexual species. The TTC method is most explicit in accommodation of asexual lineages into its delimitation process. The HZB method is most restrictive relative to conditions that must be met in nature; it requires hybrid zones and regions of sympatry between closely related species, but more such complexes are now known that could be subjected to this test [50]. Both HZB and $\mathrm{GenD}_{\mathrm{GW}}$ assume mutation/drift equilibrium, which might rarely be met in natural populations [51,52]. The $\mathrm{GenD}_{\mathrm{H}}$ protocol describes two criteria $(\mathrm{D}>0.15$, and a bimodal distribution of pairwise $\mathrm{D}$ values), and only the second of these is independent of the taxon (plethodontid salamanders) upon which the method was based.

Some methods have technological limitations. The FFR is accurate only if all alleles can be identified, because homoplasy will falsely identify different alleles as identical, and thereby lead to inferences of gene exchange when this is not the case [36]. Both allozyme [53] and microsatellite loci [54] can be characterized by allelic homoplasy between closely related species. The EXCL test 
Table 1. Empirical methods for diagnosing species boundaries, in the context of properties/criteria, classes of data, generality, and some important assumptions and/or limitations of each

\begin{tabular}{|c|c|c|c|c|c|}
\hline Method $^{a}$ & $\begin{array}{l}\text { Relevant biological } \\
\text { properties/criteria }\end{array}$ & $\begin{array}{l}\text { Classes of data suitable to } \\
\text { method }\end{array}$ & Generality $^{c}$ & Assumptions/Limitations & Refs \\
\hline \multicolumn{6}{|c|}{ Non-tree based methods } \\
\hline $\mathrm{HZB}$ & $\begin{array}{l}\text { Limited or no gene flow across } \\
\text { hybrid zone }\end{array}$ & Nuclear genes with co-dominance & $\mathrm{B}$ & $\begin{array}{l}F_{\mathrm{ST}} \text {-based } \mathrm{Nm} \text { estimator; assumes } \\
\text { drift - gene flow equilibrium, with } \\
\text { island model }\end{array}$ & {$[25]$} \\
\hline $\mathrm{GenD}_{\mathrm{GW}}$ & $\begin{array}{l}\text { Gene flow within but not between } \\
\text { species }\end{array}$ & Multilocus allele frequency data & B & $\begin{array}{l}\text { Assumes drift - gene flow } \\
\text { equilibrium }\end{array}$ & {$[27]$} \\
\hline $\operatorname{Gen}_{\mathrm{H}}$ & $\begin{array}{l}\text { Time-dependent emergence of } \\
\text { reproductive isolation }\end{array}$ & Multilocus allele frequency data & B & $\begin{array}{l}\text { Assumes a molecular clock } \\
\text { correlated with a genomic basis } \\
\text { for reproductive isolation }\end{array}$ & {$[28,29]$} \\
\hline FFR & $\begin{array}{l}\text { Recombination within nuclear loci } \\
\text { limited by extent of gene flow }\end{array}$ & Nuclear genes with co-dominance & B & $\begin{array}{l}\text { Requires identification of all } \\
\text { alleles segregating at a locus, and } \\
\text { no gene flow between species }\end{array}$ & {$[36]$} \\
\hline PAA & $\begin{array}{l}\text { Lineage isolation sufficient for } \\
\text { fixation of character states }\end{array}$ & $\begin{array}{l}\text { Allozymes, chromosomes, } \\
\text { morphology, presence/absence } \\
\text { data }\end{array}$ & $A(?), B$ & $\begin{array}{l}\text { Assumes conspecificity of } \\
\text { individuals from same locality; } \\
\text { character fixation statistically } \\
\text { difficult to show at conventional } \\
\text { levels ( } \alpha ? 0.05 \text { ) of confidence }\end{array}$ & [41] \\
\hline \multicolumn{6}{|c|}{ Tree-based methods } \\
\hline $\mathrm{CHA}$ & $\begin{array}{l}\text { Lineage isolation sufficient for } \\
\text { coalescence to monophyly of } \\
\text { haplotypes at one locus }\end{array}$ & DNA haplotypes & $A(?), B$ & $\begin{array}{l}\text { Equates non-recombinant } \\
\text { haplotype trees to species trees }\end{array}$ & {$[42]$} \\
\hline EXCL & $\begin{array}{l}\text { Lineage isolation sufficient for } \\
\text { allele coalescence to exclusivity at } \\
\text { unlinked loci }\end{array}$ & DNA haplotypes for multiple loci & $A(?), B$ & $\begin{array}{l}\text { Requires unspecified number of } \\
\text { unlinked genes with divergence } \\
\text { profiles matched to timing of } \\
\text { speciation events }\end{array}$ & {$[43]$} \\
\hline WP & $\begin{array}{l}\text { Lineage isolation sufficient for } \\
\text { geographical character } \\
\text { divergence }\end{array}$ & DNA haplotypes, morphology & $A(?), B$ & $\begin{array}{l}\text { Assumes no gene flow between } \\
\text { species; no recombination } \\
\text { between haplotypes (for DNA) }\end{array}$ & {$[11]$} \\
\hline TTC & $\begin{array}{l}\text { Lineage isolation sufficient for } \\
\text { attainment of ecological/allopatric } \\
\text { character divergence }\end{array}$ & $\begin{array}{l}\text { Genetic, ecological, } \\
\text { morphological or physiological } \\
\text { data with DNA haplotypes }\end{array}$ & $A, B$ & $\begin{array}{l}\text { Inference key can be mislead if } \\
\text { density of sampling is over- } \\
\text { dispersed; } \mathrm{H}_{2} \text { can never be } \\
\text { completely falsified; choice of } \\
\text { candidate traits may be subjective }\end{array}$ & {$[10,45]$} \\
\hline
\end{tabular}

${ }^{a}$ Abbreviations: cladistic haplotype aggregation (CHA), exclusivity criterion (EXCL), field for recombination (FFR), genetic distance Good and Wake $\left(\mathrm{Gen} \mathrm{D}_{\mathrm{GW}}\right.$ ), genetic distance Highton $\left(G e n D_{H}\right)$, hybrid zone barrier (HZB), population aggregation analysis (PAA), Templeton's tests for cohesion (TTC), Wiens and Penkrot methods (WP).

${ }^{b}$ These are deliberately general because multiple properties (criteria) are manifested during the speciation process, but both the order of their appearance and their relevance to testing species boundaries depends on many idiosyncratic conditions and mechanisms associated with a particular speciation event, and at what point along the divergence trajectory extant populations are sampled (see Fig. 5.4 in [3]).

${ }^{\mathrm{c}} \mathrm{Generality}$ refers to a method's relevance to asexual(A) and/or bisexual(B) taxa.

requires multiple unlinked genetic markers, which are often not available for some taxa [55,56]. Available methods are heavily biased in favour of the use of molecular (or at least genetic) markers, and although some stress the need for corroboration from independent data $\left(\mathrm{GenD}_{\mathrm{GW}}\right.$ and $\left.\mathrm{GenD}_{\mathrm{H}}\right)$, only PAA, WP and TTC explicitly provide for inclusion of morphological data.

All methods are sensitive to undersampling of characters and individuals, and these limitations have been addressed for some methods. The PAA requires that diagnostic character states be 'fixed' (present at $100 \%$ frequency) in species, but with few exceptions, this criterion will be unattainable at normally accepted levels of statistical confidence with finite sample sizes [8]. Wiens and Servedio [8] suggest a statistical test that incorporates an investigator established level of polymorphism as a proxy for inferring absence of gene flow (a character with states diagnosed by a $95 \%$ frequency in one sample and $5 \%$ in another), which enables one to ascertain diagnostic characters with statistical confidence in finite sample sizes (see [57], for an example). The EXCL [43] does not specify what proportion of unlinked loci must show allele monophyly for a group of samples to qualify as a genealogical species [58], although recent suggestions have specified that 'most' [59] or 50\% [60] of the sampled loci should suffice. The TTC boasts wide applicability based on dense individual, population, and character sampling; its criteria are quantitative, and because absolute categorical properties (character fixation, exclusivity, etc.) are not required, TTC can accommodate 'borderline' cases that arise from LINEAGE SORTING, hybridization, and so on, and still retrieve a clear 'signal' when species boundaries are not 'clean' [10]. However, its permutation tests [46] might be insufficiently conservative and mislead inferences under some population structures [61], and the NCA does not statistically distinguish among alternative inferences or provide estimates of uncertainty for its conclusions [62].

The emerging debates over species delimitation suggest that both systematists [3,63] and population biologists $[64,65]$ are giving the issue serious attention, and there is agreement that speciation processes create 'fuzzy' boundaries under which all methods will occasionally fail or be discordant with each other. Empirical studies bear this out: in salamanders of the Ensatina eschscholtzii complex, two 
[66], seven [67] or 11 [68] species can be recognized on the basis of different methods, a result reflecting multiple properties that change during speciation (Table 1). Given the paucity of studies comparing the performance of multiple methods [11], few generalities can be made about which methods are 'best' for a variety of taxa and biological properties, and the issue requires further comparative study.

\section{Acknowledgements}

K.A. Crandall and B. Adams commented on previous drafts of this article, and reviews by K. de Queiroz, J.J. Wiens and an anonymous referee were extremely constructive. J.W.S. has been supported by research awards from the American Museum of Natural History (Roosevelt Fund) American Philosophical Society, National Geographic Society, National Science Foundation, various state and federal conservation agencies, and the Department of Integrative Biology and the M.L. Bean Museum, BYU. J.C.M. is supported by a BYU graduate fellowship and a NSF doctoral dissertation improvement award.

\section{References}

1 Frost, D.R. and Kluge, A.G. (1994) A consideration of epistemology in systematic biology, with special reference to species. Cladistics 10 , 259-294

2 Mayden, R.L. (1997) A hierarchy of species concepts: the denouement in the saga of the species problem. In Species: The Units of Biodiversity (Claridge, M.F. et al., eds), pp. 381-424, Chapman and Hall

3 De Queiroz, K. (1998) The general lineage concept of species, species criteria, and the process of speciation. In Endless Forms: Species and Speciation (Howard, D.J. and Berlocher, S.H., eds), pp. 57-75, Oxford University Press

4 Wiens, J.J. (1999) Polymorphism in systematics and comparative biology. Annu. Rev. Ecol. Syst. 30, 327-362

5 Wiley, E.O. and Mayden, R. (2000) The evolutionary species concept. In Species Concepts and Phylogenetic Theory: A Debate (Wheeler, Q.D. and Meier, R., eds), pp. 70-89, Columbia University Press

6 Wheeler, Q.D., Meier, R. eds (2000) Species Concepts and Phylogenetic Theory: A Debate, Columbia University Press

7 Mayr, E. (1982) The Growth of Biological Thought, Harvard University Press

8 Wiens, J.J. and Servedio, M.R. (2000) Species delimitation in systematics: inferring diagnostic differences between species. Proc. R. Soc. Lond. Ser. B. 267, 631-636

9 Puorto, G. et al. (2001) Combining mitochondrial DNA sequences and morphological data to infer species boundaries: phylogeography of lanceheaded pitvipers in the Brazilian Atlantic forest, and the status of Bothrops pradoi (Squamata: Serpentes: Viperidae). J. Evol. Biol. 14, $527-538$

10 Templeton, A.R. (2001) Using phylogeographic analyses of gene trees to test species status and boundaries. Mol. Ecol. 10, 779-791

11 Wiens, J.J. and Penkrot, T.A. (2002) Delimiting species using DNA and morphological variation and discordant species limits in spiny lizards (Sceloporus). Syst. Biol. 51, 69-91

12 Hughes, J.B. et al. (1997) Population diversity: its extent and extinction. Science 278, 689-692

13 Coyne, J. et al. (1997) A critique of Sewall Wright's shifting balance theory of evolution. Evolution 51, 643-671

14 Wade, M.J. and Goodnight, C. (1998) Perspective: the theories of Fisher and Wright in the context of metapopulations: when nature does many small experiments. Evolution 52, 1537-1553

15 Barton, N.H. and Gale, K. (1993) Genetic analysis of hybrid zones. In Hybrid Zones and the Evolutionary Process (Harrison, R.G., ed.), pp. 13-45, Oxford University Press

16 Brown, J.H. et al. (1996) The geographic range: size, shape, boundaries, and internal structure. Annu. Rev. Ecol. Syst. 27, 597-623

17 Blackburn, T.M. and Gaston, K.J. (1998) Some methodological issues in macroecology. Am. Nat. 151, 68-83

18 Barraclough, T.G. and Nee, S. (2001) Phylogenetics and speciation. Trends Ecol. Evol. 16, 391-399

19 Sites, J.W. Jr and Crandall, K.A. (1997) Testing species boundaries in biodiversity studies. Conserv. Biol. 11, 1289-1297
20 Peterson, A.T. and Navarro-Sigüenza, A.G. (1999) Alternate species concepts as bases for determining priority conservation areas. Conserv. Biol. 13, 427-431

21 Mallet, J. (1995) A species definition for the modern synthesis. Trends Ecol. Evol. 10, 294-299

22 Baum, D.A. and Donoghue, M.J. (1995) Choosing among alternative 'phylogenetic' species concepts. Syst. Bot. 20, 560-573

23 Brooks, D.R. and McLennan, D.A. (1999) Species: turning a conundrum into a research program. J. Nematol. 31, 117-133

24 Mishler, B.D. and Theriot, E.C. (2000) The phylogenetic species concept (sensu Mishler and Theriot): monophyly, apomorphy, and phylogenetic species concepts. In Species Concepts and Phylogenetic Theory: A Debate (Wheeler, Q.D. and Meier, R., eds), pp. 44-54, Columbia University Press

25 Porter, A.H. (1990) Testing nominal species boundaries using gene flow statistics: the taxonomy of two hybridizing admiral butterflies (Limenitis: Nymphalidae). Syst. Zool. 39, 131-147

26 Wright, S. (1931) Evolution in Mendelian populations. Genetics 16, 97-159

27 Good, D.A. and Wake, D.B. (1992) Geographic variation and speciation in the torrent salamanders of the genus Rhyacotriton (Caudata:Rhyacotritonidae). Uni. Calif. Pub. Zool. 126, 1-91

28 Highton, R. (1989) Biochemical evolution in the slimy salamanders of the Plethodon glutinosus complex in the eastern United States. Part I. Geographic protein variation. Ill. Biol. Monogr. 57, 1-78

29 Highton, R. (1990) Taxonomic treatment of genetically differentiated populations. Herpetologica 46, 114-121

30 Nei, M. (1972) Genetic distance between populations. Am. Nat. 106, 283-292

31 Baverstock, P.R. et al. (1977) Electrophoretic comparisons between allopatric populations of five Australian pseudomyine rodents (Muridae). Aust. J. Biol. Sci. 30, 471-485

32 Thorpe, J.P. (1982) The molecular clock hypothesis: biochemical evaluation, genetic differentiation and systematics. Annu. Rev. Ecol. Syst. 13, 139-168

33 Highton, R. (1998) Is Ensatina a ring species? Herpetologica 54, $254-278$

34 Highton, R. (2000) Detecting cryptic species using allozyme data. In The Biology of Plethodontid Salamanders (Bruce, R.C. et al., eds), pp. 215-241, Kluwer Academic/Plenum Publishers

35 Coyne, J.A. and Orr, A.H. (1998) The evolutionary genetics of speciation. Philos. Trans. R. Soc. Lond. Ser. B 353, 287-305

36 Doyle, J. (1995) The irrelevance of allele tree topologies for species delimitation, and a non-topological alternative. Syst. Bot. 20, 574-588

37 Carson, H.L. (1957) The species as a field for recombination. In The Species Problem (Mayr, E., ed.), pp. 23-38, American Association for the Advancement of Science

38 Avise, J.C. and Ball, R.M. (1990) Principles of genealogical concordance in species concepts and biological taxonomy. Oxf. Surv. Evol. Biol. 7, 45-67

39 Avise, J.C. and Wollenberg, K. (1997) Phylogenetics and the origin of species. Proc. Natl. Acad. Sci. U. S. A. 94, 7748-7755

40 Ayala, F.J. and Hartl, D.L. (1993) Molecular drift of the Bride of Sevenless (boss) gene in Drosophila. Mol. Biol. Evol. 10, 1030-1040

41 Davis, J.I. and Nixon, K.C. (1992) Populations, genetic variation, and the delimitation of phylogenetic species. Syst. Biol. 41, 421-435

42 Brower, A.V.Z. (1999) Delimitation of phylogenetic species with DNA sequences: a critique of Davis and Nixon's population aggregation analysis. Syst. Biol. 48, 199-213

43 Baum, D.A. and Shaw, K.L. (1995) Genealogical perspectives on the species problem. In Experimental and Molecular Approaches to Plant Biosystematics (Hoch, P.C. and Stephenson, A.G., eds), pp. 289-303, Missouri Botanical Garden

44 Templeton, A.R. et al. (1995) Separating population structure from history: a cladistic analysis of the geographical distribution of mitochondrial DNA haplotype in the tiger salamander, Ambystoma tigrinum. Genetics 140, 767-782

45 Templeton, A.R. (1998) Nested clade analyses of phylogeographic data: testing hypotheses about gene flow and population history. Mol. Ecol. $7,381-397$

46 Posada, D. et al. (2000) GEODIS: a program for the cladistic nested analysis of the geographic distribution of genetic haplotypes. Mol. Ecol. 9, 817-818 
47 Templeton, A.R. (1994) The role of molecular genetics in speciation studies. In Molecular Ecology and Evolution: Approaches and Application (Schierwater, B. et al., eds), pp. 455-477, Birkhäuser Verlag

48 Templeton, A.R. (1999) Using gene trees to infer species from testable null hypotheses: cohesion species in the Spalax ehrenbergi complex. In Evolutionary Theory and Process: Modern Perspectives, Papers in Honour of Eviatar Nevo (Wasser, S.P., ed.), pp. 171-192, Kluwer Academic Publishers

49 Shaw, K.L. (1999) A nested analysis of song groups and species boundaries in the Hawaiian cricket genus Laupala. Mol. Phylogenet. Evol. 11, 332-341

50 Arnold, M.L. (1997) Natural Hybridization and Evolution, Oxford University Press

51 Pannell, J.R. and Charlesworth, B. (1999) Neutral genetic diversity in a metapopulation with recurrent local extinction and recolonization. Evolution 53, 664-676

52 Whitlock, M.C. and McCauley, D.E. (1999) Indirect measures of gene flow and migration: $\mathrm{F}_{\mathrm{ST}} \neq 1 /(4 \mathrm{Nm}+1)$. Heredity 82 , $117-125$

53 Murphy, R.W. (1996) Proteins: isozyme electrophoresis. In Molecular Systematics (Hillis, D.M. et al., eds), pp. 51-120, Sinauer Associates

54 Estoup, A. et al. (2002) Homoplasy and mutation model at microsatellite loci and their consequences for population genetic analysis. Mol. Ecol. 11, 1591-1604

55 Hare, M.P. (2001) Prospects for nuclear gene phylogeography. Trends Ecol. Evol. 16, 700-706

56 Zhang, D-X. and Hewitt, G.M. (2003) Nuclear DNA analyses in genetic studies of populations: practice, problems, and prospects. Mol. Ecol. $12,563-584$

57 Benavides, E. et al. (2002) Species boundaries among the Telmatobius
(Anura: Leptodactylidae) of the Lake Titicaca basin: allozyme and morphological evidence. Herpetologica 58, 31-55

58 Hudson, R.R. and Coyne, J.A. (2002) Mathematical consequences of the genealogical species concept. Evolution 56, 1557-1565

59 Shaw, K.L. (2001) The genealogical view of speciation. J. Evol. Biol. 14, $880-882$

60 Shaw, K.L. (2002) Conflict between nuclear and mitochondrial DNA phylogenies of a recent species radiation: what mtDNA reveals and conceals about modes of speciation in Hawaiian crickets. Proc. Natl. Acad. Sci. U. S. A. 99, 16122-16127

61 Petit, R.J. and Grivet, D. (2002) Optimal randomization strategies when testing the existence of phylogeographic structure. Genetics 161, 169-171

62 Knowles, L.L. and Maddison, W.P. (2002) Statistical parsimony. Mol. Ecol. 11, 2623-2635

63 Frost, D. (2000) Species, descriptive efficiency, and progress in systematics. In The Biology of Plethodontid Salamanders (Bruce, R.C. et al., eds), pp. 7-29, Kluwer Academic/Plenum Publishers

64 Harrison, R.G. (1998) Linking evolutionary pattern and process. The relevance of species concepts for the study of speciation. In Endless Forms: Species and Speciation (Howard, D.J. and Berlocher, S.H., eds), pp. 19-31, Oxford University Press

$65 \mathrm{Wu}, \mathrm{C}-\mathrm{I}$. (2001) The genetic view of the process of speciation. J. Evol. Biol. 14, 851-865

66 Frost, D.R. and Hillis, D.M. (1990) Species in concept and practice: herpetological applications. Herpetologica 46, 87-104

67 Graybeal, A. (1995) Naming species. Syst. Biol. 44, 237-250

68 Highton, R. (1998) Is Ensatina eschscholtzii a ring-species? Herpetologica 54, 254-278

69 Swofford, D.L. (2001) PAUP*: Phylogenetic Analysis Using Parsimony (*and Other Methods), Sinauer

\section{Could you name the most significant papers published in life sciences this month?}

Updated daily, Research Update presents short, easy-to-read commentary on the latest hot papers, enabling you to keep abreast with advances across the life sciences.

Written by laboratory scientists with a keen understanding of their field, Research Update will clarify the significance and future impact of this research.

Our experienced in-house team is under the guidance of a panel of experts from across the life sciences who offer suggestions and advice to ensure that we have high calibre authors and have spotted the 'hot' papers.

Visit the Research Update daily at http://update.bmn.com and sign up for email alerts to make sure you don't miss a thing.

This is your chance to have your opinion read by the life science community, if you would like to contribute, contact us at research.update@elsevier.com 